Yahya Elsaghe

Thomas Mann auf Leinwand und Bildschirm 



\section{Yahya Elsaghe}

Thomas Mann

auf Leinwand

und Bildschirm

Zur deutschen Aneignung seines Erzählwerks in der langen Nachkriegszeit 
ISBN 978-3-11-063480-8

e-ISBN (PDF) 978-3-11-063850-9

e-ISBN (EPUB) 978-3-11-063542-3

Library of Congress Control Number: 2019945618

Bibliografische Information der Deutschen Nationalbibliothek

Die Deutsche Nationalbibliothek verzeichnet diese Publikation in der Deutschen Nationalbibliografie; detaillierte bibliografische Daten sind im Internet über http://dnb.dnb.de abrufbar.

(C) 2019 Walter de Gruyter GmbH, Berlin/Boston

Druck und Bindung: $\mathrm{CPI}$ books $\mathrm{GmbH}$, Leck

Coverabbildung: Filmstill aus Die Bekenntnisse des Hochstaplers Felix Krull (1982; Regie: Bernhard Sinke)

www.degruyter.com 
Für Katharina Teutsch und Elsa Elsaghe 
